\title{
Antonio Maceo en Costa Rica a fines del siglo XIX: ¿Un intelectual orgánico de su época?
}

Antonio Maceo in Costa Rica at the end of 19th century: An organic intellectual of his time?

Antonio Alvarez Pitaluga

Sede Regional Chorotega, Universidad Nacional, Costa Rica

antonio.alvarez.pitaluga@una.cr

Recibido: 02/10/2018 • Aceptado: 30/09/2019

\section{RESUMEN}

Con perspectiva filosófica e histórica, el artículo analiza una faceta del independentista cubano Antonio Maceo escasamente investigada por las historiografías de Cuba y Costa Rica: su condición de intelectual orgánico de su época. A partir de una caracterización histórica sobre dicho tipo de intelectual, se valora cómo Maceo adquirió tal condición, así como el papel que tuvo el liberalismo costarricense a finales del siglo XIX para alcanzarla. Se pretende demostrar que esta condición ha sido mayormente soslayada a pesar de su existencia histórica, para la cual Costa Rica brindó un contexto social muy favorable durante la estancia que desarrolló la mítica figura caribeña.

Palabras clave: Intelectuales, sociedad, independencia, liberalismo, modernidad. 


\begin{abstract}
With a philosophical and historical perspective, the article proposes to analyze a social facet, scarcely investigated by the historiographies of Cuba and Costa Rica, of the prominent Cuban pro-independence Antonio Maceo: his status as an organic intellectual of his time. From a historical characterization on this type of intellectual, it is analyzed how Maceo acquired such a condition, as well as the role that liberalism and its ideas had in Costa Rica at the end of the XIX century to complete it. It is also intended to demonstrate that this condition has been largely ignored despite its historical existence, for which Costa Rica provided a very favorable social context during the stay that developed the mythical Caribbean personality.
\end{abstract}

Keywords: Intellectuals, society, independence, liberalism, modernity.

\title{
EL INTELECTUAL DE LA MODERNIDAD
}

Desde los albores de la modernidad, la figura del intelectual fue redefinida como la de un sujeto que legitimaría con sus funciones la nueva sociedad capitalista. Es probable que la vida pública y la obra escrita de Nicolás Maquiavelo (1469-1527) hayan sido de los primeros ejemplos de la nueva inserción intelectual. Desde ambas, el florentino instaba a una lectura dual de la realidad social. Asimismo, abogaba por una moralidad para la sociedad en emersión y sus miembros; a su vez, entendía otra moralidad para el funcionamiento del Estado y sus gobernantes. Esa incipiente duplicidad interpretativa fue estableciendo de manera gradual los campos de acción del intelectual en la modernidad, la sociedad y el Estado en construcción.

Como parte de aquel rediseño histórico, inserto en la expansión del nuevo modelo social capitalista de Occidente, el liberalismo inglés (siglo XVII) y el iluminismo francés (siglo XVIII) dividieron el Estado y la sociedad como entidades autónomas sin interrelaciones recíprocas. En tal delineación, la cultura fue presentada como poderoso instrumento de liberación del pasado, que no se mezclaba con la política, señalando a la primera como vía esencial de la emancipación individual; mientras que, la segunda quedaba reservada para las nuevas clases y grupos económicos encabezados por la burguesía que capitalizaba los poderes políticos de los Estados 
nacionales. De ese modo, ambas fueron definidas bajo el doble binomio de separación, cultura-sociedad y política-Estado.

Las dos construcciones ideológicas se configuraron entonces como estructuras no relacionadas entre sí; por consiguiente, sus representantes quedaron igualmente separados en la cartografía estatal moderna, es decir, el político y el intelectual. El primero era el encargado de representar y dirigir básicamente la política del Estado y sus estructuras gubernamentales; mientras que, el segundo se delineó como el reproductor y divulgador del sistema a partir de su producción escrita y artística, sin concebir su participación en la política. Su relación con ella era a partir de su rechazo a través de críticas constantes, que por efecto lo separaban de la política, del Estado y de los políticos. Así, el poder político y sus sistemas de relaciones garantizaban, entre otras acciones, la no incumbencia directa del último en sus asuntos y sus dinámicas de funcionamiento.

Dicha imagen y esquema relacional se forjó entre los siglos XVI y finales del XIX. En igual periodo de tiempo, el mercado capitalista en expansión fue diseñando modelos sociales acorde a sus intereses, sobre todo en Occidente. Dentro de tales esquemas fue recalcado el papel liberador de la cultura frente a un pasado (Antiguo régimen desde la Revolución francesa de 1789), que ya no se ajustaba a las nuevas necesidades liberales, concibiendo así la imagen que hoy llega de la cultura renacentista y sus creadores. Esa visión fragmentada de la cultura es manejada por muchos hasta el presente, al igual que en el pensamiento social se concibe la fragmentación de las ciencias sociales.

Sin embargo, su condición de vital instrumento de dominación no fue tan pregonada. La doble condición de la cultura, instrumento de liberación y a un mismo tiempo de dominación, fue declarada y descrita abiertamente desde mediados del siglo XIX en los estudios de Carlos Marx (1818-1883), cuando ya el Estado capitalista había desplegado sus hilos de dominación para el ejercicio del poder a través de la cultura artística y literaria, así como de la emergente prensa escrita.

En ese complejo proceso de formación del capitalismo occidental se fue forjando la clásica imagen que todavía hoy muchos manejan del intelectual: sujeto social acumulador de saberes y conocimientos, almacenador de datos, reproductor de conocimientos, de esquemas y estructuras sociales, 
poseedor de una alta capacidad de crítica al Estado y sus políticas. El realismo crítico del siglo XIX reforzó su proyección individual y colectiva de incomprendidos, solitarios, rebeldes sociales, creadores encerrados en torres de babel, reacios sociales, bohemios irremediables con un profundo hastío por sociedad. Pero la imagen y la tradición del intelectual renacentista-liberal entraron en una profunda crisis a partir del periodo 1871-1914, cuando el liberalismo doctrinal cayó en una honda crisis de paradigmas. Las causales históricas fueron varias y memorables.

Desde la década del cuarenta del siglo XIX, la filosofía moderna comenzó a identificar y caracterizar las nuevas relaciones sociales y de poder generadas por el joven capitalismo europeo. Estas se estructuraron a partir de los nuevos sentidos sociales que adquirió la mercancía como forma de circulación no solo material de la plusvalía, sino también inmaterial. La mercancía se hizo portadora de los valores materiales y espirituales del sistema, devino en expresión cultural de la producción de las fuerzas dominantes con un contenido social. El poder de la hegemonía dominante no solo comenzaba a expresarse a partir de sus estructuras políticas, sino, además, a través de todos los intersticios de la sociedad por donde circulaban las mercancías que alcanzaban los espacios públicos y privados del sujeto; por lo que el intelectual, que hasta ese momento reproducía la ideología de las estructuras políticas, ya no se ajustaba a las nuevas realidades. Fue entonces preciso concebir otro intelectual de nuevo tipo, capaz de comprender y desenvolverse en cada esfera social y de poder de la sociedad capitalista y, a su vez, que se convirtiese en un importante agente para las vías del cambio ante la crisis de dicha sociedad.

En esa coyuntura, el pensador Antonio Gramsci (1891-1936) reelaboró el concepto del intelectual conocido hasta ese entonces. Para él, la nueva circunstancia exigía de otro tipo de intelectual, capaz de participar activamente en la conformación del tejido orgánico de la sociedad que superaría la crisis liberal y los cambios sociales que de ella se derivasen, pero no solo mediante la reproducción o la crítica de los valores y la ideología dominante, sino, además, en la producción de tales ideas y valores para crear y recrear las diferentes estructuras hegemónicas del Estado. Ante los ojos del pensador italiano, la arquitectura hegemónica se había expandido a través de esferas como la economía, la administración, la política, la burocracia, las fuerzas armadas y otras. En ese proceso, la literatura y el 
arte fueron articulados como vitales vasos comunicantes de la producción y reproducción de las hegemonías.

Era preciso proyectar un intelectual que desde su campo cultural (estructuras mencionadas) fuese creador del nuevo tejido orgánico, de una organicidad social que respondiera a la expansión molecular del Estado y a la crisis doctrinal de liberalismo para convertirlo en participante esencial y dinámico de las funciones organizativas de la producción del Estado (Acanda, 2007). Se trataba de un papel social que, hasta ese momento, el intelectual cumplía muy poco o no le estaba asignado. El nuevo modelo sería, entonces, participante directo de la construcción de la arquitectura del poder y sus estructuras hegemónicas, pero no solo como refrendador o crítico de estas hasta ese momento, sino también como un importante productor de sus ideas, modelos y estructuras sistémicas más allá de sus banderas ideológicas. Devendría en un participante-creador de la administración y los discursos de la economía, la educación, de la burocracia y la política.

En esa perspectiva, el maestro, el dirigente político, el burócrata, un funcionario de la administración o la burocracia y hasta el promotor cultural de una simple comunidad, pasarían a ser intelectuales en la misma medida en que lo era el escritor o el artista más aclamado. De igual modo, el político también pasó a ser un intelectual, ahora de nuevo tipo: orgánico. El intelectual orgánico de Gramsci asume la crítica social como necesidad permanente de mejoramiento constructivo y reformador, superando así la crítica de los primeros, los intelectuales tradicionales, asociada todavía hoy a la mera protesta o la inconformidad social. El intelectual orgánico, junto a otras figuras públicas, produce y reproduce el tejido orgánico de la sociedad.

Su papel en los campos culturales de cualquier sociedad inmersa en la modernidad se codifica mediante su participación en la producción y reproducción de ideas y de la ideología que representa. Es un agente creador de ambas que se desenvuelve en un circuito y gremios de intelectuales agrupados por afinidades políticas, económicas, religiosas, artísticas-literarias y sociales, formando así los denominados campos intelectuales.

Ahora bien, el intelectual orgánico no elimina ni tampoco niega la existencia del tradicional. Ambos coexisten en las sociedades modernas. Los dos forman parte de la conciencia crítica de las clases y grupos que forman la sociedad. Esta convivencia también permite comprender mejor que el 
llamado problema o malestar de los intelectuales se codifica a partir del agrupamiento de ellos entre los que se insertan dentro de las estructuras del poder político y los que están fuera de ella. Por tanto, la organicidad del intelectual en la modernidad no se establece desde sus militancias políticas, sino desde sus asunciones sociales, "el intelectual, en la sociedad moderna, es orgánico a la hegemonía o la contrahegemonía, más allá de que milite o no en algún organismo político (...)" Acanda (2007, p. 263).

\section{El intelectual de la independencia de América Latina del siglo XIX desde la historiografía}

La historiografía latinoamericana sobre el ciclo emancipador continental del siglo XIX ha visto mayormente la figura y papel del intelectual en su sentido tradicional (Dym \& Alfredo, 2014). En tal sentido, separó las funciones y los protagonismos de militares, políticos, escritores, pensadores y estadistas que desempeñaron distintos roles a lo largo de la emancipación americana entre 1790 y 1826, de la Revolución haitiana al Congreso Anfictiónico de Panamá (Guerra, 2015).

Después de finalizar el ciclo emancipador, el intelectual tradicional siguió teniendo una sostenida presencia en el periodo de las reformas liberales entre finales de la década del cuarenta y el fin del siglo XIX. Es importante recordar el papel educativo de estos intelectuales llamados "científicos" en el gobierno mexicano Benito Juárez (Azula, 2006). Durante el extenso ciclo de inserción capitalista de América Latina (1830-1910), el papel del intelectual tuvo un protagonismo sustancial en la formación de la conciencia nacional y los estados nacionales. Desde Costa Rica, el papel de este tipo de intelectual en Centroamérica durante la etapa liberal ha sido investigado de maneras muy interesantes (Molina, 2004).

Sin embargo, antes de concluir el siglo decimonónico comenzaron a aparecer figuras cuyas actuaciones públicas rompieron ese molde conceptual. Probablemente, la personalidad continental que mejor simbolizó tal ruptura fue la de José Martí. Fue un abogado y hombre de letras que dejó una obra escrita en 27 tomos en apenas 42 años de vida, compuesta de textos de periodismo, teatro, poesía, ensayo, crítica literaria y artística, reflexiones políticas, filosóficas y económicas. Pero si bien tampoco se discuten sus condiciones de iniciador del modernismo iberoamericano, fundó y dirigió a un mismo tiempo, con este cúmulo creativo, un partido político para 
organizar arduamente la última guerra por la independencia de Cuba. Murió como participante militar en sus primeros combates, hecho no habitual en la época entre los intelectuales tradicionales del continente. Fue, además, el primero de los intelectuales latinoamericanos de la segunda mitad del XIX que entendió la necesidad de una segunda independencia continental. Su pensamiento llegó mucho más allá de la formación o modernización del Estado liberal, abogando por un humanismo de raíces latinoamericanas:

A lo que es, allí donde se gobierna, hay que atender para gobernar bien; y el buen gobernante en América no es el que sabe cómo se gobierna el alemán o el francés, sino el que sabe con qué elementos está hecho su país, y cómo puede ir guiándolos en junto, para llegar, por métodos e instituciones nacidas del país mismo, a aquel estado apetecible donde cada hombre se conoce y ejerce, y disfrutan todos de la abundancia que la naturaleza puso para todos en el pueblo que fecundan con su trabajo y defienden con sus vidas. El gobierno ha de nacer del país. El espíritu del gobierno ha de ser el del país. La forma del gobierno ha de avenirse a la constitución propia del país. El gobierno no es más que el equilibrio de los elementos naturales del país. (Martí, 1891, p.1).

Para él, la política era una vía y una extensión de la cultura y viceversa, por lo que su proyección lo distanció del intelectual tradicional y lo acercó definitivamente al orgánico. En Cuba ha sido visto por muchos como el intelectual orgánico cimero de la independencia, mientras que Antonio Maceo, Máximo Gómez y otros dirigentes o protagonistas de la independencia entre 1868-1898 han sido asumidos mayormente hasta hoy como dirigentes políticos o militares, restringiendo sus actuaciones y quehaceres a una de esas dos áreas o a las dos, pero sin configurarlos como intelectuales orgánicos de aquel cambio social.

\section{ELINTELECTUALANTONIOMACEO,RAZONESDEUNAPOSPOSICIÓN}

En la historiografía cubana, Antonio Maceo ha sido visto no pocas veces como un dirigente militar y político a través de sus hazañas bélicas, actuaciones políticas y sus periplos latinoamericanos. Tal construcción histórica le ha negado hasta los inicios del siglo XXI, consciente o inconscientemente, la condición y la imagen de intelectual del cambio social insular de finales del siglo XX. ¿Por qué ha ocurrido esto? Las razones son varias, al enumerarlas 
puede presentárselas bajo el siguiente enunciado: la evolución y desarrollo de un profundo nacionalismo bélico-oposicional cubano, a través de la formación de la nación cubana, ha determinado las imágenes y presentaciones históricas e historiográficas de Antonio Maceo hasta el presente.

Si bien la Isla comenzó desfasadamente su ciclo independentista en 1868, cuando prácticamente el resto de América Latina ya lo había concluido formalmente desde 1826, su estallido y desarrollo generó una tradición bélica promovida desde una importante producción literaria conocida como Literatura de campaña, compuesta de poemarios, dramas, testimonios, obras de teatro, cuentos y muchos diarios de campaña, escritos por los propios actores civiles y militares de las contiendas. En esta literatura, el protagonismo de los dirigentes civiles y militares inauguró una tradición de existencia dual donde progresivamente los primeros fueron responsabilizados mayormente por los desaciertos cometidos a lo largo de tres contiendas, 1868, 1879 y 1895.

Las denominaciones de civiles y militares permitieron esbozar en dos grupos, no solo a sus principales y destacadas figuras, sino además, y de modo general, a los dos tipos de dirigentes que acertada o desacertadamente condujeron las riendas de la independencia. De tal manera, el civil, voluntaria o involuntariamente, era asociado a un intelectual problemático que hubo de poner trabas al proceso independentista o no estuvo a la altura del cambio deseado por él, salvo contadas excepciones como la de José Martí. Al arribar el año 1959, de modo casi inmediato, este comenzó a ser legitimado en aquel pasado independentista de 1868-1898. Entre 1959 y 1968 se catalizó sobremanera en el discurso historiográfico del país una lógica explicativa de la formación nacional cubana a partir de los procesos bélicos de los siglos XIX y XX. Desde ella, se ha expuesto hasta la actualidad una buena parte la formación de la nacionalidad y la nación cubanas desde 1868. No obstante, el nacionalismo cubano ya venía estructurándose mucho antes de esa fecha por oposición y enfrentamientos a fuerzas exógenas que en diferentes momentos de la historia trataron de imponerse.

Desde el año 1959, la imagen histórica e historiográfica del combatiente independentista del siglo XIX, de la cual proviene la figura de Maceo, fue notablemente politizada dentro del proceso de legitimación ya mencionado. De ese modo, la historia fue dotada de funciones ideológicas muy 
marcadas desde 1959. El Estado tuvo, entonces, su mayor fuente de legitimación en la historia (Zanetti, 2009).

Lo anterior viabilizó la exaltación permanente de los protagonistas de la independencia como directores políticos-militares o militares antecesores directos de los triunfadores de 1959, dejando postergado en algunos casos y relegados en otros, sus condiciones de intelectuales productores de la organicidad independentista de la nación. Excepto para la figura de Martí, el calificativo de intelectual resultaba incómodo para dirigentes militares procedentes de la tradición independentista. Pero la proyección intelectual de Antonio Maceo tendría otro hándicap mucho antes de 1959. Ya antes de caer en combate en 1896, su figura comenzó a ser encuadrada como un guerrero eminente. A las fuerzas y grupos no favorables a la independencia armada del país no les interesaba reconocer su quehacer intelectual en aras de la organicidad que aspiraba. José Martí (1893) alertó con temor esa construcción de su imagen, cuando en el periódico Patria afirmó en tono de aclaración "Maceo tiene tanta fuerza en su mente como en su brazo" (Martí, 1893, p. 454).

De modo general, los historiadores e investigadores de Maceo durante el siglo XX ahondaron en sus cualidades como jefe militar y dirigente político, dejado en un segundo plano su condición de intelectual orgánico. Pueden proponerse cuatro causas fundamentales que pudieron haber contribuido a tal negación, consciente o inconscientemente. Estas se presentan en los siguientes párrafos como negaciones.

Primera negación. Las clases dominantes a finales del periodo colonial y a lo largo de la primera mitad del siglo XX (la república neocolonial) construyeron una imagen histórica de un Maceo luchador y combatiente, dirigente militar y héroe popular, pero no de un pensador portador de un pensamiento anticolonial; a lo sumo, un hacedor del mismo pero no uno de sus principales creadores. Por tanto, fue perfilada en la historiografía nacional durante esos años un Maceo patriota, inclaudicable, militar luchador, pero de muy pobre dinámica intelectual, tanto tradicional como orgánica. No obstante, es reconocible una corriente historiográfica que durante el periodo republicano resaltó su pensamiento político en autores como Emilio Roig (1955) y José Luciano Franco (1975), pero el Maceo militar y combatiente fue el prevaleciente en la escritura histórica y los imaginarios populares de entonces. 
Segunda negación. La Revolución de 1959 se legitimará rápidamente en las luchas anticoloniales del siglo XIX, ya que necesitaba homologarse en sus luchas y dirigentes, así como en los combatientes independentistas como clase dirigente iniciadora de la cadena histórica 1868,1895 y 1959. Se potenció, entonces, un Maceo militar en detrimento de sus condiciones intelectuales. Estas no fueron abandonadas, se continuaron estudiando, pero su divulgación no estuvo en función de delinear y estudiar la imagen del intelectual orgánico.

Tercera negación. También, las divergencias entre la vanguardia política y la vanguardia artista-literaria en la Revolución desde finales de los años sesenta del pasado siglo XX propiciaron la reproducción progresiva del Maceo militar-dirigente político, del militar como figura histórica de los procesos independentistas, antes que la asociación con la incómoda imagen que se fue generando por esos años entre los intelectuales orgánicos-dirigente sobre el intelectual situado fuera de las estructuras hegemónicas. De ese modo, la figura intelectual de Maceo cayó en la compleja madeja de la llamada cuestión de los intelectuales.

Cuarta negación. Desde fines de los sesenta del pasado siglo, la ideología marxista asumió gradualmente en Cuba varios componentes de la versión ortodoxa del marxismo, la que separa la cultura del Estado y adjudicando formalmente al intelectual tradicional como reproductor del poder y sus estructuras. De tal manera, una parte de la intelectualidad fue vista dentro de la histórica tradición de escritores formados bajo los cánones del realismo crítico del siglo XIX europeo; es decir, productores de una espiritualidad artística y literaria propensos al inconformismo social. Desde ese esquema mental e ideológico, Maceo no encuadraba como un intelectual, tampoco sería un escritor o productor de una obra de marcada organicidad independentista. Sus reconocimientos vendrían por la vía armada o la política en su sentido tradicional.

Una vez definidas estas adversidades históricas e historiográficas que han impedido sumir plenamente a Antonio Maceo como un intelectual orgánico de su tiempo, es necesario preguntarse, ¿fue verdaderamente Maceo un intelectual orgánico de su época? ¿fue productor de la organicidad independentista o un destacado hacedor de esta? Antes de hallar ambas respuestas, es necesario acotar que forma consciente e inconsciente hubo una resistencia a responderlas, con un apego a la tradición que retardó 
una y otra vez tal suposición (Álvarez, 2012). Sin embargo, hoy se considera cierta y necesaria. La dialéctica del cambio permite evolucionar sobre pensamientos propios.

Podría considerarse que la menor producción escrita del Titán de Bronce frente a las extensas obras escriturales de José Martí y Máximo Gómez era un elemento más que suficiente para no desplazar su imagen a la condición de intelectual orgánico del independentismo. Pero la teoría social enseña que la obra del intelectual orgánico no se mide por la cantidad de textos escritos, sino por su grado de participación, conciencia y maneras de desenvolverse en su realidad social. Por tanto, Antonio Maceo fue sin lugar a dudas un intelectual orgánico de su época.

Quizás muchos historiadores han pretendido colocarlo voluntaria o involuntariamente al lado de José Martí para medir o compararlo con la altura intelectual del Delegado del Partido Revolucionario Cubano, pero este último no fue la media de la intelectualidad orgánica del independentismo cubano. Por el contrario, su magnífico intelecto a escala continental fue una excepcionalidad difícil de igualar por otros intelectuales cubanos y latinoamericanos de su tiempo. Maceo, desde su propia intensidad formativa y productora, no solo fue reproductor de un ideal de independencia, sino también un creador y productor de ella.

Su actuación pública a lo largo de su vida fue portadora de asunciones políticas y de valores sociales con los cuales proyectó desplazar la vieja sociedad colonial junto al resto de la intelectualidad radical de la Cuba de su época. Su quehacer muestra que generó y promovió un particular discurso anticolonial que hoy forma parte de la narrativa épica nacional más allá de sus usos e ideologizaciones contemporáneas. Sus fundamentos estribaron en aspectos tales como el antiesclavismo, la igualdad social, la liberación nacional como esencia de la lucha armada, su posición anticorruptiva, una independencia nacional sin dependencias extranjeras y una moral altruista acorde con el romanticismo del siglo XIX, plasmada dentro y fuera de su producción escrita.

De su experiencia latinoamericana más extensa y rica, su estancia en Costa Rica entre 1891 y 1895 recibió las mayores informaciones y aplicaciones prácticas del liberalismo burgués como pensamiento avanzado de su 
época. Si bien no era suficiente para la independencia que aspiraba, sí superaba en varios sentidos el recalcitrante colonialismo español.

\section{COSTARICA,DIFERENCIASORGÁNICASENTREDOSINTELECTUALES INDEPENDENTISTAS: ANTONIO MACEO Y ANTONIO ZAMBRANA}

Recientemente el académico costarricense Miguel Calderón publicó un interesante ensayo sobre las cercanías y contacto que tuvo Maceo con el liberalismo epocal de América Latina a través de su eclosión costarricense (Calderón, 2016). De su lectura, se puede definir y comprender cuáles fueron las experiencias liberales que pudo haber tomado de aquella realidad nacional para su formación y quehacer intelectual. De modo general, pudiera decirse que la Costa Rica finisecular debió haber influenciado en su proyección intelectual independentista en cuanto a:

- $\quad$ El proceso de construcción (en desarrollo por aquel entonces) de la independencia costarricense desde los sucesos bélicos de 1856-1857. Los liberales costarricenses sentaron su pensamiento en este mito fundacional de carácter nacionalista y en otros del siglo XIX asociados a la independencia del país. Probablemente, Maceo los conoció a través de la oralidad y las diversas fuentes escritas a la que tuvo acceso, como los periódicos del momento. La independencia, desde un trampolín bélico, fue una asociación común con la independencia de la Isla y de muchos otros estados latinoamericanos del siglo decimonónico.

- La solidaridad costarricense con los procesos liberales e independentista en ese instante histórico que facilitaron el tránsito por el país de varios dirigentes liberales latinoamericanos, como el ecuatoriano Eloy Alfaro con quien Maceo tenía una franca amistad.

- $\quad$ El modelo en formación del intelectual liberal costarricense, con el cual tuvo contactos y relaciones a través de varios de sus representantes. De ellos, se pueden percibir sus relaciones con las estructuras del poder desde las cuales la formal independencia política era un factor indispensable para la construcción del estado nacional.

- La experiencia de ver y llegar a participar indirectamente en el sistema presidencialista del país, que en Cuba no conoció al ser una colonia española hasta 1898 (Franco, 1975). 
- $\quad$ Finalmente, los procesos y acontecimientos en torno a la construcción del Estado-nación que apreció durante sus años en Costa Rica.

En igual contexto liberal, otro destacado intelectual cubano asumió con distinta organicidad el tema de la independencia insular. Se trató de Antonio Zambrana (1846-1822), uno de los representantes más importantes de la dirigencia civil mambisa de los primeros años de la Guerra Grande. Fue uno de los dos redactores de la primera constitución cubana conocida como Constitución de Guáimaro (1869), asambleísta del conclave y representante a la Cámara de Representante, primer órgano legislativo de los patriotas insulares. Si bien sus diferencias con la dirección política de la revolución lo hicieron abandonar Cuba a mediados de 1873, su prestigio como redactor de la constitución lo acompañó para el resto de su vida. En Costa Rica, hizo una larga y prestigiosa carrera profesional como abogado y docente que lo convirtieron hasta el día de hoy en unos de los padres fundadores de la jurisprudencia costarricense (Vargas, 2006). El peso de su impronta en la formación de intelectuales costarricense lo podemos ver en una impresión que años más tarde escribió el político Teodoro Picado:

Yo recuerdo cómo para mi padre era el Doctor Zambrana poco menos que un Dios tutelar (...) Creo fue uno de los hombres que contribuyeron eficazmente a sentar las bases del pensamiento liberal costarricense, que a su vez sustentó nuestra vida democrática en toda una etapa histórica (Picado, 1947, p.1).

En suelo costarricense, las fricciones con Antonio Maceo no fueron pocas, tanto que del plano político pasaron al personal en más de una ocasión. Las agrias polémicas entre ambos tuvieron como denominador común sus diferentes asunciones orgánicas sobre la independencia de Cuba. Para Maceo, la revolución armada era una cuestión esencial para la soberanía nacional, mientras que Zambrana (1896) veía en el evolucionismo social y no armado la solución más viable para Cuba, "Creer que la única evolución es la radical, que es el único camino que conduce en menos tiempo; que no hay pleito que se deba transigir (...) Precisamente sostengo todo lo contrario" (Archivo Nacional de Cuba, Fondo Donativos y Remisiones, 1896).

Las palabras de Zambrana recibieron desde años atrás, y en más de una ocasión, el apoyo público de sus antiguos discípulos. Uno de ellos fue el notable periodista Pío Víquez (1893), quien desde su periódico tuvo frases 
de respaldo como estas: "se dice por todas partes que la dictadura está prefiriendo para generales de operaciones a ciertos graduados de Cuba en revolución contra España; graduados de general que muy poco importan a lo coyoles o cocos costarricenses" (Víquez, 1893, El Heraldo de Costa Rica). En la historiografía cubana, ambos se representan respectivamente como ejemplos de luz y sombra del independentismo.

La razón fundamental de tal diferenciación, vista hoy desde una perspectiva política, no estriba en su salida de la guerra y su posterior militancia en el Partido Autonomista en la década de los ochenta, sino en el hecho de que siendo un intelectual emergido en la vorágine revolucionaria no logró articular a lo largo de su vida una organicidad revolucionaria. Su asunción orgánica navegó con tropiezos, pero irreversiblemente hacia el liberalismo tradicional decimonónico. Escribió una importante obra, gestada casi toda fuera de Cuba. Maceo tuvo una menor producción frente al abogado habanero, pero los grados de compromiso orgánicos en torno al independentismo insular de cada uno sirven de ejemplo sobre el hecho de que, más allá de la extensión de una obra escrita, la asunción orgánica mental e ideológica del intelectual logra determinar mucho más el grado de pertenencia al acontecimiento revolucionario o social.

Durante el siglo XIX, las independencias latinoamericanas fueron incompletas, generando los graves problemas y dilemas de continuidad de dependencia a potencias foráneas como Inglaterra y Estados Unidos. Aunque en relación con el último país, las desventajosas relaciones se ahondaron progresivamente con el inicio y decurso del siglo XX. Sujeta una mayor profundidad investigativa, consideró hasta el día de hoy que la presencia de intelectuales tradicionales y la ausencia de intelectualidades nacionales de perspectiva orgánica coadyuvaron a la penetración de estas potencias (Guerra, 2003). De haber existido estas últimas, tal vez hubieran infundido más radicalizaciones a los respectivos procesos independentistas continentales.

\section{LAS VISIONES LATINOAMERICANAS DE SU INTELECTUALIDAD ORGÁNICA}

El conjunto interpretativo de la visión intelectual maceista en torno a la América Latina de su época es aún un tema pendiente en la historiografía cubana. La tendencia a la hora de presentar el latinoamericanismo de Maceo se ha centrado en su contenido informativo. Se le ha concedido a Antonio Maceo 
una proyección latinoamericana, pero todavía lo escrito por los historiadores no es suficiente para conocer y comprender con toda la magnitud debida cómo veía e interpretaba Maceo la realidad histórica y social del continente, es decir, su pensamiento latinoamericano. Destacar algunas frases e ideas de esa visión, citar fechas de entrada y salida de países latinoamericanos que visitó, esbozar planes revolucionarios y los encuentros con figuras continentales de su época, no son suficientes para sistematizar un pensamiento que necesita ser reconstruido e interpretado a fondo todavía.

Tentativamente, un camino investigativo en tal dirección puede nutrirse de un grupo de ideas que pudieran coadyuvar a las futuras hipótesis de trabajo, entre ellas sobresalen:

- El sentido latinoamericanista de su lucha y actuación pública quedó asentado en el espíritu revolucionario y romántico del XIX, entendiendo el último no como una actitud poética o meramente altruista, sino como su profundo sentido de la vida en los hombres del siglo XX.

- El ideal del estado laico que la modernidad liberal infundió en la vida pública de la segunda mitad del siglo XIX y los procesos independentistas de esa época fueron determinantes en su latinoamericanismo.

- La igualdad social que define el pensamiento de Antonio Maceo partió del hecho definitorio e irreversible de la abolición de la esclavitud en Cuba.

- La creación del estado-nación latinoamericano como un modelo a seguir tuvo, para él, en Costa Rica el ejemplo más conocido, que no significa que haya sido el más acabado a nivel continental. Entre las características que más pudieron haber influido en él estuvieron: la exaltación a la independencia política de un país previa ruptura colonial, el apoyo a las ideas de progreso tecnológico y social de la época, la formación de una identidad nacional al igual que sucedía en Cuba, entre otras.

- $\quad$ Por último, la globalidad de estas ideas que, junto a otras sobre la independencia y la realidad epocal de Cuba, sedimentaron su condición de intelectual orgánico del independentismo insular en la propia medida que uno de sus mayores dirigentes militar y político. 


\section{CONCLUSIONES}

Los más recientes progresos y perspectivas de las historiografías de Cuba y Costa Rica ya permiten comenzar a demostrar que Antonio Maceo fue un importante intelectual orgánico de su país y su época histórica. A lo largo de más de un siglo de historiografía cubana, la imagen de Maceo ha sido construida de modo general como una figura militar, dejando pospuesta su contrapartida intelectual. Las razones para asumir tal dimensión fueron planteadas a modo de negaciones en el cuerpo del artículo.

Esa otra visión social y filosófica tiene, desde ambos países, ricas posibilidades documentales y bibliográficas para ser desarrollada hasta sus máximas posibilidades. Es un tema incipiente aún en las dos historiografías, que pueden contribuir a profundizar el análisis de las temáticas asociadas a la participación de los intelectuales orgánicos en los procesos de formación nacional, a niveles nacionales y continentales.

Si bien las independencias latinoamericanas fueron dirigidas, en muchos casos, por grupos y figuras militares y políticas, dar paso desde esta mirada histórica al estudio de esos y otros sectores participantes como intelectuales orgánicos, sería un importante avance para las investigaciones históricas sobre dichos procesos emancipadores. Este artículo ha intentado comenzar a avanzar en esa dirección. Para hacerlo, el engranaje conceptual e interpretativo entre la historia y la filosofía moderna fue un eje fundamental.

La reflexión expuesta corroboró, además, que el periplo de Maceo por varios países de América Latina influenció, según cada caso, en las asunciones intelectuales de su quehacer político y público. En el concierto de naciones visitadas, su estancia en Costa Rica (1891-1895) tuvo, de manera esencial, el mayor peso formativo en su proyección intelectual en cuanto a varias características del Estado moderno a instaurar en Cuba, una vez lograda su independencia.

Con virtudes y defectos, el modelo de liberalismo latinoamericano que con mayor detenimiento pudo conocer de primera mano, fue el costarricense. No articulado de modo total en la sociedad de Costa Rica para el momento del regreso a su tierra natal, le aportó no pocos elementos como para diseñar un esquema propio de sociedad superadora de los desmanes del colonialismo ibérico. 
Si bien historiadores cubanos y costarricenses desde hace años han estudiado su pensamiento político, las investigaciones sobre la dimensión continental y orgánica de este aún tienen un buen sendero por recorrer. No obstante, de manera preliminar, también se puede concluir que la organicidad de Antonio Maceo rebasa su conocido compromiso con la independencia de Cuba y tiene una sólida base que lo convierte en un definitivo intelectual orgánico de su época. Parafraseando al autor de los Cuadernos de la Cárcel, el poder de su organicidad radica en la conciencia que tuvo sobre las realidades sociales de Cuba y América Latina.

\section{REFERENCIAS}

Acanda, J. L. (2007). Traducir a Gramsci. La Habana, Cuba: Editorial de Ciencias Sociales.

Álvarez, A. (2012). Revolución, hegemonía y poder. Cuba 1895-1898. La Habana, Cuba: Fundación Fernando Ortiz.

Archivo Nacional de Cuba. (1896). Fondo Donativos y Remisiones. Expediente Antonio Zambrana Vázquez, "Colaboración”, 24 de enero de 1896.

Azula, L. F. (2006). El proyecto científico juarista. Revista Digital Universitaria, 7(3), 1-8. Recuperado de http://132.248.9.34/hevila/Revistadigitaluniversitaria/2006/vol7/no3/2.pdf

Calderón, M. (2016). Liberalismo: contextos y encuentros con Antonio Maceo. En A. Álvarez, \& E. Barboza (coords.). Costa Rica en Antonio Maceo. San José, Costa Rica: Editorial Arlequín.

Dym, J. \& Alfredo, S. A. (coord.). (2014). Centroamérica durante las revoluciones atlánticas: el vocabulario político 1750-1850. San Salvador, EI Salvador: IEESFORD Editores.

Franco, J. L. (1975). Antonio Maceo. Apuntes para una historia de su vida. La Habana, Cuba: Editorial de Ciencias Sociales.

Guerra, S. (2003). El dilema de la independencia. La Habana, Cuba: Editorial Félix Varela. 
Guerra, S. (2015). Nueva historia mínima de América Latina. Biografía de un continente. República Dominicana: Archivo General de la Nación.

Martí, J. (10 de enero de 1891). Nuestra América. Revista La Revista llustrada de Nueva York, pp. 1-6.

Martí, J. (6 de octubre de 1893). Antonio Maceo. Periódico Patria. En, José Martí Obras Completas (1975). La Habana, Cuba: Editorial de Ciencias Sociales, tomo IV, p. 454.

Molina, I. (2004). La estela de la pluma: cultura impresa e intelectuales en Centroamérica durante los siglos XIX y XX. San José, Costa Rica: EUNA.

Picado, T. (17 de octubre de 1947). Carta de Teodoro Picado a Gerardo Rodríguez Morejón. Periódico Diario de La Marina. En Biblioteca Nacional de Cuba, Sala Cubana, Colección Diario de la Marina.

Roig, E. (1955). La Guerra Cubanohispana fue ganada por el Lugarteniente General del Ejército Libertador Calixto García. La Habana, Cuba: Municipio de La Habana, Oficina del Historiador de la Ciudad.

Vargas, A. (2006). El doctor Zambrana. San José: Costa Rica: Editorial UNED.

Víquez, P. (4 de marzo de1893). Editorial. El Heraldo de Costa Rica. En Archivo Nacional de Costa Rica.

Zanetti, O. (2009). Pasado para un futuro. Acerca de los usos y la utilidad de la historia. Revista La Gaceta de Cuba. (1), pp. 6-10. 